\title{
Resíduos eletroeletrônicos: ações do Batalhão Ambiental Mirim na sensibilização da comunidade de Faxinal do Soturno, RS
}

\author{
Electroelectronic waste: actions of Environmental Mirim Squad in awareness of \\ the Faxinal do Soturno community, RS
}

\author{
Volnei Chelotti ${ }^{1}$, Ísis Samara Ruschel Pasquali ${ }^{2}$, Daniele Guarienti Rorato ${ }^{3}$ \\ 1. Universidade Federal de Santa Maria, RS, Brasil, Tecnólogo em Agricultura Familiar, Especialista em Educação \\ Ambiental, Faxinal do Soturno, RS, Brasil \\ 2. Universidade Federal de Santa Maria, RS, Brasil, Bióloga. Prof. Drª . do Curso de Especialização em Educação \\ Ambiental da UFSM, Santa Maria, RS, Brasil \\ 3. Universidade Federal de Santa Maria, RS, Brasil, Engenheira Florestal, M.Sc, Doutoranda do PPG Engenharia \\ Florestal da UFSM, Santa Maria, RS, Brasil
}

\begin{abstract}
Resumo
Esse trabalho teve como objetivo apresentar as atividades desenvolvidas pelo Batalhão Ambiental Mirim da Escola Estadual de Educação Básica Dom Antônio Reis, Faxinal do Soturno, RS, como uma ferramenta prática de educação ambiental. A proposta de criação desse Batalhão surgiu basicamente do interesse de alunos, os quais demonstraram preocupação com o meio ambiente, em especial, com o descarte de resíduos eletrônicos. O grupo realiza atividades de coleta de resíduos eletrônicos na cidade, associado a práticas de conscientização durante a coleta, bem como participação em feiras e eventos municipais. Esse Batalhão Ambiental Mirim é considerado um grupo de trabalho recente, com apenas dois anos de atuação. Durante o ano de 2014, foram coletados três toneladas de resíduos eletrônicos, as quais foram vendidas a uma empresa especializada. Comparativamente ao ano de 2013, uma tonelada a mais foi recolhida, devido, possivelmente, a divulgação e reconhecimento do Batalhão e suas atividades na sensibilização da comunidade. Assim, visa-se aumentar o envolvimento dos alunos participantes do Batalhão para atuarem como multiplicadores de uma consciência ambiental por meio, principalmente, do descarte adequado e consciente de resíduos eletrônicos, contribuindo com a redução, mesmo que em escala local, dos impactos causados pelo crescente descarte desses resíduos.
\end{abstract}

Palavras-chave: Resíduo eletroeletrônico. Meio ambiente. Educação Ambiental.

\begin{abstract}
This work aimed to present the activities developed by the Environmental Mirim Squad of the State School of Basic Education Dom Antonio Reis, Faxinal do Soturno, RS, as a practical tool for environmental education. The proposed creation of this Squad basically came from the interest of students, who were concerned with the environment, in particular the disposal of electronic waste. The group conducts electronic waste collect activities in the city, associated with awareness of practices in the collect, as well as participation in fairs and local events. This Environmental Mirim Squad is considered a recent working group, with only two years of operation. During 2014, were collected three tons of electronic wastes, which were sold to a specialized company. Compared to the year 2013 a ton more was collected, due possibly the dissemination and recognition of the Squad and its activities in community. Thus, the aim is to increase the participants involvement Squad students to act as multipliers of environmental awareness through mainly appropriate and conscious disposal of electronic waste, contributing to the reduction, even on a local scale, the impacts caused by increasing disposal of such waste.
\end{abstract}

Keywords: Electroelectronic waste. Environment. Environmental education. 


\section{Introdução}

A preocupação com o meio ambiente vem crescendo ao longo dos anos, devido aos problemas ambientais enfrentados. Entre esses problemas, o aumento populacional vem causando, além da necessidade de expansão das áreas agrícolas para suprir a demanda por alimentos, um acúmulo desenfreado de resíduos gerados todos os dias pelas diversas atividades humanas.

Um tipo de resíduo que vem se destacando pela enorme quantidade que vem sendo descartado são os Resíduos Eletroeletrônicos (REEs) ou simplesmente lixo eletrônico como também é conhecido popularmente (NATUME; SANT'ANNA, 2011). A cadeia produtiva desses produtos é classificada em quatro diferentes linhas: linha marrom, verde, branca e azul (RUIZ; KNIESS; TEIXEIRA, 2014). Segundo esses autores, a linha marrom é formada por televisor tubo/monitor, televisor plasma/LCD/monitor, DVD/VHS e produtos de áudio; a linha verde por desktops, notebooks, impressoras e aparelhos celulares; a linha branca por geladeiras, refrigeradores, congeladores, fogões, lava-roupas, ar-condicionado; e a linha azul por batedeiras, liquidificadores, ferros elétricos e furadeiras.

Esses produtos, que com o avanço tecnológico trazem agilidade para a vida da população, vêm sendo substituídos rapidamente por novas versões. Essa substituição em massa aliada a um descarte inadequado está acarretando um problema ambiental relevante que é o grande volume de lixo tecnológico, composto por metais pesados, encontrados em lixões comuns. Conforme Lima, Silva e Lima (2008), o lixo tecnológico é o gênero de resíduo que mais cresce no mundo, e no Brasil, Rodrigues (2007) relatou a produção desse tipo de resíduo estimada em 2,6 Kg por habitante/ano.

Esses materiais, na maioria dos casos, não passam por nenhum processo de reciclagem e quando descartados em locais inadequados causam risco de contaminação para o meio ambiente e para o homem, além de prejuízos econômicos e sociais. Conforme Andrade, Fonseca e Mattos (2010), os prejuízos econômicos decorrem da necessidade de extração de novas matérias-primas para a síntese de produtos e da necessidade de investimento financeiro para movimentar toda a cadeia produtiva. Em termos sociais, esses autores relataram que os maiores danos são ocasionados aos trabalhadores, que manuseiam diretamente esses resíduos sem as condições apropriadas de segurança.

Concomitante as perdas econômicas e sociais, os prejuízos para o meio ambiente são causados, principalmente, pelos constituintes dos eletroeletrônicos, os quais segundo Natume e Sant'Anna (2011) os metais representam mais de $70 \%$ da composição. Os metais pesados, ao entrarem em contato com o solo, contaminam as águas superficiais e os lençóis subterrâneos e, se queimados, poluem o ar além de prejudicar a saúde dos catadores que entrarem em contato com esses resíduos (CELERE et al., 2007).

Preocupados com essas e outras questões ambientais, alunos da Escola Estadual de Educação Básica Dom Antônio Reis (EEEBDAR) de Faxinal do Soturno, RS, mobilizaram-se e criaram, de maneira oficial, o Batalhão Ambiental Mirim da EEEBDAR. Os alunos e membros responsáveis realizam diversas atividades, entre elas a coleta de resíduos eletrônicos associada a um trabalho educativo que visa auxiliar na conscientização da população local com relação ao descarte adequado desses e de outros tipos de materiais.

Ações práticas como essas são de fundamental importância na formação da consciência ambiental. O envolvimento de crianças e adultos em ações ambientais proporciona um aprendizado construtivo e permanente, possibilitando assim, uma real e significativa mudança comportamental nesses indivíduos, os quais passam a apresentar comprometimento com o meio ambiente, atuando como multiplicadores desse conhecimento. Nesse sentido, Scardua (2010) relatou a necessidade de praticar uma educação centrada não só no conhecimento-razão, mas também voltada para os valores, atitudes e princípios ambientais e de vida em sociedade. Assim, somente com o envolvimento e comprometimento de toda a sociedade é possível alcançar uma real sensibilização da população, a qual se reflete em hábitos conscientes de descarte de eletrônicos. 
Diante do exposto, o presente trabalho objetivou apresentar o Batalhão Ambiental Mirim da EEEBDAR, Faxinal do Soturno, RS, como exemplo de ferramenta de educação ambiental e incentivo para a criação de batalhões em outras escolas.

\section{Material e Métodos}

O Batalhão Ambiental Mirim da EEEBDAR, de Faxinal do Soturno, RS, deu início as suas atividades em janeiro de 2013. Contudo, sua proposta de criação surgiu no ano de 2012, basicamente, do interesse de alunos de determinadas turmas da Escola, os quais durante as aulas da disciplina de Agroecologia demonstraram além do interesse pelas práticas agroecológicas, preocupação com o meio ambiente, em especial, com o descarte de resíduos eletrônicos.

Assim, foi elaborada uma proposta, a qual foi apresentada ao Diretor da Escola. Após sua concordância, o Batalhão deu início, já em janeiro de 2013, mesmo que de maneira informal, as atividades de coleta de resíduos eletrônicos na cidade. Paralelamente a isso, foram sendo obtidas informações sobre os procedimentos para formalização do Batalhão junto ao município.

Desse modo, o Batalhão Ambiental Mirim da EEEBDAR de Faxinal do Soturno, foi aprovado, oficialmente, no dia 24 de setembro de 2013, durante reunião ordinária do Conselho do Meio Ambiente local, realizada no auditório municipal, sendo aprovada por unanimidade pelos membros do Conselho ali presentes. Contudo, como as atividades vinham sendo realizadas desde o início de 2013, considera-se que, até os dias atuais, o presente Batalhão está atuando há dois anos.

O Batalhão Ambiental Mirim é composto por, aproximadamente, 60 integrantes, todos alunos da Escola sob supervisão do Professor da disciplina de Agroecologia da mesma. A maioria dos componentes são alunos dos $8^{\circ}$ anos e das $8^{a}$ séries da EEEBDAR, possuem idade que varia de 13 a 15 anos, e residem na zona urbana do Município.

As atividades do Batalhão ocorrem duas vezes por semana, no turno inverso das aulas da EEEBDAR, no qual os integrantes realizam a segregação, separação e classificação dos resíduos eletrônicos armazenados. Também, uma vez por mês, todos os componentes reúnem-se e divididos em pequenos grupos realizam atividades externas de coleta de resíduos eletroeletrônicos e panfletagem, em residências e estabelecimentos comerciais do município bem como participação em eventos e feiras locais visando à divulgação do Batalhão e de suas ações, participação no Programa "Rádio Escola" desenvolvido pela EEEBDAR e que conta com o apoio de rádios locais para sua divulgação. Além disso, é realizada a destinação correta desses resíduos, anualmente, mediante venda do material coletado a empresa terceirizada do setor.

A descrição das ações do Batalhão Ambiental Mirim da EEEBDAR de Faxinal do Soturno, RS, trata-se de uma pesquisa descritiva e com relação ao delineamento, enquadra-se como estudo de caso (GIL, 2008). Além disso, essa pesquisa foi considerada como quali-quatitativa, pois além de apresentar aspectos qualitativos envolvidos no trabalho, apresenta também aspectos quantitativos, como o peso de resíduos coletados, o número de alunos envolvidos e as atividades realizadas.

\section{Resultados e Discussão}

\subsection{Coleta, segregação e destinação dos resíduos eletrônicos}

O Batalhão Ambiental Mirim da EEEBDAR foi criado com o objetivo de buscar a sensibilização e formação da consciência ambiental da comunidade de Faxinal do Soturno, visando à minimização de impactos negativos ao ambiente como forma de preservação da qualidade ambiental, entre outras finalidades. A iniciativa de formação desse Grupo veio, inicialmente, de quatro alunos e um professor, entretanto hoje já são 60 alunos, quatro professores, além de membros da comunidade que trabalham juntos nas ações ambientais. 
Desde sua criação o grupo atuou em diversas atividades, todas com a participação direta dos alunos e o acompanhamento e supervisão do Professor da disciplina de Agroecologia. O apoio da Secretaria do Meio Ambiente de Faxinal do Soturno e do Poder Público também é importante, pois fortalecem o trabalho desempenhado pelo Batalhão Ambiental Mirim, fazendo com que esse possa desenvolver ações concretas dentro do Município.

Inicialmente, o retorno da comunidade era pequeno, mas com o tempo foi possível perceber a aceitação e participação da mesma, pois já é perceptível, nesse curto período de atuação do Batalhão, mudanças comportamentais tanto da população em geral como em alguns representantes comerciais. Dentre as ações realizadas até o momento, a que mais se destacou foi a coleta de resíduos eletrônicos. O destaque se deve a quantidade de material coletado, o qual totalizou, aproximadamente, duas toneladas. Essa ação ocorreu no ano de 2013 e devido a grande quantidade de material coletado foi realizada novamente em 2014.

O Batalhão Ambiental Mirim da EEEBDAR desenvolve, mensalmente, um encontro no qual todos os integrantes comparecem, e divididos em grupos menores de cinco ou seis pessoas, realizam a coleta dos resíduos eletrônicos nas residências e no comércio local do Município. O grupo visita as moradias e também lojas comerciais potenciais geradoras desse tipo de resíduo para apresentar suas atividades e sensibilizar a população para que participem dos dias de coleta. Nesse dia, o grupo coleta qualquer tipo de resíduo eletrônico. A coleta de eletrônicos é realizada em todas as residências do município e tem duração de um dia útil, e ocorre com frequência quinzenal.

Durante as visitas às residências e estabelecimentos comerciais, também se realiza a entrega de panfletos informativos. O panfleto apresenta aos munícipes orientações a respeito da limpeza dos terrenos baldios da cidade, a qual é de responsabilidade dos proprietários, bem como informações sobre as atividades desenvolvidas pelo Batalhão Ambiental Mirim e esclarecimentos sobre a coleta de resíduos eletrônicos.

No momento em que realizam a visita e a coleta de resíduos eletroeletrônicos, os membros do Batalhão Ambiental Mirim realizam a leitura e explanam aos munícipes sobre a importância do descarte adequado desse tipo de resíduo, bem como informam a população sobre as atividades do Grupo.

Após a coleta, o material é transportado até uma sala cedida pela Secretaria do Meio Ambiente, da Prefeitura Municipal de Faxinal do Soturno, que serve como depósito de todo o material arrecadado durante o ano. O local disponibilizado para armazenamento dos resíduos coletados anualmente, além de servir como depósito do material e também para a realização dos trabalhos de segregação e classificação dos materiais, serve também como um PEV (ponto de entrega voluntária).

Concomitante a coleta, duas vezes por semana, no turno inverso das aulas da Escola, os integrantes do Batalhão se reúnem no depósito e fazem o desmanche, separação e classificação dos resíduos eletrônicos armazenados. Nesse momento, os aparelhos eletrônicos são fracionados e suas partes são separadas, basicamente, em fiação, material plástico e vidro. Também, durante esses dois dias semanais realizam-se panfletagens nas ruas do Município.

Cabe destacar que entre os resíduos eletrônicos mais descartados pela população estão, em primeiro lugar, aparelhos celulares, seguidos de videocassetes, computadores e televisores.

Desde o início de suas atividades no ano de 2013, todo o resíduo recolhido, separado e fracionado durante o ano foi quantificado e entregue a uma empresa especializada de Santa Maria, RS. Essa quantificação e recolhimento final ocorrem normalmente no mês de dezembro de cada ano e é feito por uma empresa terceirizada.

No ano de 2013, o resíduo recolhido foi quantificado e doado a essa Empresa. Já no ano de 2014, todo o resíduo armazenado em 2014 foi quantificado e vendido para a mesma. Conforme pode ser observado na Figura 1, evidenciou-se um aumento na quantidade em toneladas de resíduos recolhidos, quando comparados os anos de 2013 e 2014. 


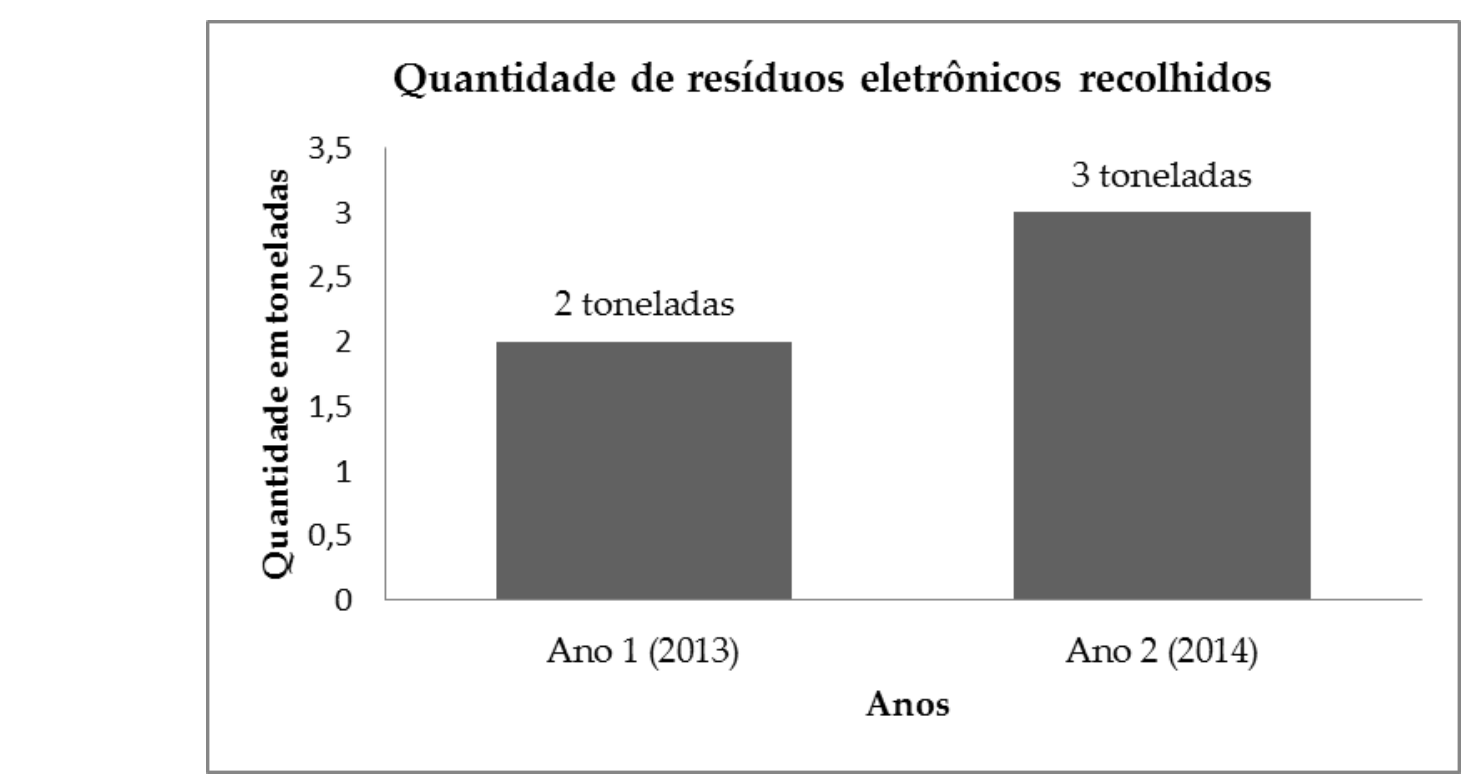

Figura 1 - Quantificação do resíduo eletrônico coletado nos anos de 2013 e 2014 pelo Batalhão Ambiental Mirim da EEEBDAR, Faxinal do Soturno, RS.

Esse aumento na quantidade de resíduos coletados pode ser atribuído, principalmente, ao constante desenvolvimento tecnológico e a influência do capitalismo no cotidiano da população, o qual faz com que produtos sejam produzidos e consumidos com rapidez (ANDRADE; FONSECA; MATTOS, 2010). Isso gera a cada dia equipamentos mais modernos e funcionais que fazem com que os considerados "antigos", "obsoletos", "ultrapassados" e até mesmo "sem utilidade", sejam descartados em massa.

Além dessa questão, o aumento na quantidade de resíduo eletrônico acumulado pelo Batalhão na segunda quantificação pode ter aumentado devido ao maior reconhecimento da população local às atividades desse Grupo, fato esse que pode ser atribuído a todas as atividades de divulgação realizadas pelo mesmo, incluindo também as redes sociais.

\subsection{Atividades de sensibilização e solução de problemas ambientais locais}

Desde a aprovação oficial, os integrantes do Batalhão Ambiental Mirim são convidados a participar das reuniões da Secretaria do Meio Ambiente. Em uma das reuniões, o Batalhão foi convidado a participar das atividades da Semana da Água do Município, em outubro de 2013. Nessa ocasião, o Batalhão Ambiental Mirim apresentou-se e realizou atividades como a leitura de textos e mensagens e dinâmicas sobre a importância da água para a comunidade. Todas as atividades desenvolvidas junto à comunidade nesse momento visaram, além da apresentação do Grupo (recentemente fundado oficialmente no Município), aproximar a comunidade da temática ambiental, especialmente do tema água, de forma descontraída, mediante sensibilização dos presentes. Conforme Bozza et al. (2005), é necessário interligar informações com ações práticas, pois a realização de atos concretos proporciona uma aprendizagem significativa, relevante e contextualizada.

Além disso, o Batalhão realiza mutirões de conscientização, como o realizado durante a $22^{\underline{a}}$ EXPOFAX e a 10 ${ }^{a}$ EXPOCOLÔNIA, Feiras Municipais que ocorreram juntas, nos dias 01 a 04 de Maio de 2014. Na ocasião, o grupo contava com um estande de divulgação para demonstrar ao público visitante, oriundo não só do município de Faxinal do Soturno, mas também das demais cidades que compõe a Quarta Colônia de Imigração Italiana, as atividades desenvolvidas pelo Batalhão.

Durante os dias de realização das Feiras, os integrantes demonstravam aos interessados a maneira correta de separar os resíduos, especialmente aqueles produzidos durante o próprio evento. $\mathrm{Na}$ 
ocasião, foram separados materiais plásticos, papel, metal e vidro. Ao final, todo o material devidamente separado foi doado para catadores autônomos do Município.

Além disso, o Batalhão Ambiental Mirim possui participação no Programa "Rádio Escola" desenvolvido pela EEEBDAR e que conta com o apoio das rádios locais (AM/FM) para sua divulgação. Nesses programas, de ocorrência semanal, os alunos têm 30 minutos para divulgar os trabalhos e resultados obtidos bem como realizar entrevistas. Todas essas atividades visam divulgar as ações do Batalhão a toda a comunidade e região, visto a ampla abrangência desse tipo de mídia.

\subsection{Desafios futuros para o Batalhão Ambiental Mirim}

Por se tratar de um trabalho pioneiro na região e pelo curto período de tempo de atuação, inúmeras dificuldades são encontradas pelo Grupo. Essas não são vistas como dificuldades para o andamento das atividades, mas sim como desafios futuros para melhorar o trabalho que vem sendo desenvolvido.

Entre esses desafios, cabe destacar a carência de um veículo utilitário para que o Batalhão possa realizar a coleta de resíduos eletrônicos com mais segurança para os integrantes.

Além disso, cita-se como desafios:

- Aumentar o número de professores envolvidos e incluir também representantes da comunidade local e da Prefeitura Municipal;

- Criar um cadastro de Empresas/Estabelecimentos Comerciais no Município que possuam resíduos eletrônicos para descarte, passível de ser expandido para outros municípios da Quarta Colônia de Imigração Italiana;

- Criação de um selo “Empresa Amiga do Meio Ambiente e do Batalhão Ambiental Mirim da EEEBDAR" para aqueles comerciantes que aderirem à proposta;

- Quantificar, ao longo do tempo, os resíduos coletados anualmente, para possibilitar comparações futuras;

- Apresentar e possibilitar a divulgação das atividades do Batalhão Ambiental Mirim da EEEBDAR em outros municípios, especialmente os da Quarta Colônia de Imigração Italiana e;

- Apoiar a criação de outros Batalhões em outros municípios, especialmente os da Quarta Colônia de Imigração Italiana.

\subsection{Envolvimento dos alunos participantes do Batalhão Ambiental Mirim}

Como mencionado anteriormente, a iniciativa de formação do Batalhão veio de um grupo de quatro alunos. Contudo, com a formalização do grupo, o andamento das atividades e principalmente, com a visualização dos resultados, outros alunos passaram a ter interesse em participar. Esse interesse foi além dos alunos inicialmente previstos dos $8^{\mathrm{o}}$ anos e das $8^{\mathrm{a}}$ séries. Alunos dos anos iniciais e do ensino médio também demonstraram interesse.

A cada dia, os alunos demonstram maior comprometimento, interesse e envolvimento com as atividades do Batalhão, mas acima de tudo, com a problemática ambiental, relatando o anseio de ver o município em que vivem como referência ambiental, mediante descarte adequado de resíduos eletrônicos, coleta seletiva de lixo, entre outros.

Com o decorrer e o fortalecimento das ações desenvolvidas pelo Batalhão, todos os integrantes desejam sensibilizar e envolver outros alunos e também divulgar as ações do Batalhão. Isso tornará possível que outras Escolas se interessem e criem o seu próprio batalhão, expandindo-se assim, práticas ambientalmente corretas para outros municípios e comunidades.

Adicionalmente, um público cada vez maior, seja no meio urbano ou rural, estará sendo atingido. Assim, espera-se que essas iniciativas se reflitam em ações, mas acima de tudo, em mudanças comportamentais individuais e coletivas, as quais possibilitarão um meio ambiente mais equilibrado, com sustentabilidade dos recursos naturais e melhor qualidade de vida. 


\section{Conclusão}

O Batalhão Ambiental Mirim da EEEBDAR de Faxinal do Soturno, RS, realiza atividades de coleta de resíduos eletroeletrônicos associada à panfletagem junto à comunidade e estabelecimentos comerciais do Município tanto na área urbana como na rural; segregação e destinação adequada do material coletado; participação em eventos e feiras municipais bem como no Programa Rádio Escola.

A iniciativa de formação do Batalhão veio de quatro alunos e um professor, entretanto hoje já são 60 alunos, quatro professores, além de membros da comunidade que trabalham juntos nas ações ambientais.

Durante o ano de 2014 foram coletadas três toneladas de resíduos eletrônicos. Comparativamente ao ano de 2013, uma tonelada a mais foi recolhida, devido, possivelmente a divulgação e reconhecimento do Batalhão e suas atividades pela comunidade.

O Batalhão Ambiental Mirim da EEEBDAR é considerado um grupo de trabalho recente e pioneiro na região, com apenas dois anos de atuação, que visa à sensibilização ambiental por meio, principalmente, do descarte adequado e consciente de resíduos eletrônicos. Tais práticas contribuem para minimizar, mesmo que em escala local, os impactos causados pelo crescente descarte desse tipo de resíduo.

Com a consolidação do Batalhão Ambiental Mirim e com a superação dos desafios enfrentados pelo Grupo no presente, espera-se estimular e despertar o interesse de outros alunos da Escola e também da população local com relação à temática ambiental.

\section{Referências bibliográficas}

ANDRADE, R. T. G.; FONSECA, C. S. M.; MATTOS, K. M. C. Geração e destino dos resíduos eletrônicos de informática nas instituições de ensino superior de Natal - RN. Holos, Natal, 2010,v.2: p.100-112.

BOZZA, A. N. et al. Conscientização sobre a importância da mata ciliar realizada com alunos do ensino fundamental da escola sistema educacional Realidade, Campinas SP. 2005. Disponível em: http://www.enapet.ufsc.br/anais/conscientizacao_sobre_a_importancia_da_mata_ciliar_realizada_com _alunos_do_ensino_fundamental_da_escola_sistema_educacional_realidade_campinas-sp.pdf. Acesso em: 15 dezembro de 2014.

CELERE. M. S; OLIVEIRA, A. S.; TREVILATO, T. M. B.; SEGURA-MUNOZ, S. I. Metais presentes no chorume coletado no aterro sanitário de Ribeirão Preto, São Paulo, Brasil, e sua relevância para saúde pública. Cadernos de Saúde Pública, 2007,v. 23 (n. 4): p. 939-947.

GIL, A. C. Métodos e Técnicas de Pesquisa Social. 6. ed. São Paulo: Editora Atlas, 2008, 220p.

LIMA, M. L. M; SILVA, J. B; LIMA, J. E. Manufatura reversa e o gerenciamento adequado do lixo eletrônico. In: IX Seminário Nacional de Resíduos Sólidos - por uma gestão integrada e sustentável, 2008, Palmas. Anais do IX Seminário Nacional sobre Resíduos Sólidos: por uma gestão integrada e sustentável, 22 a 25 de outubro, Palmas, TO , 2008. 
NATUME, R. Y.; SANT'ANNA, F. S. P. Resíduos Eletroeletrônicos: Um Desafio Para o Desenvolvimento Sustentável e a Nova Lei da Política Nacional de Resíduos Sólidos. In: $3^{\text {rd }}$ International Workshop Advances in Cleaner Production. São Paulo. Maio, 2011.

RODRIGUES, A. C. Impactos socioambientais dos resíduos de equipamentos elétricos e eletrônicos: estudo da cadeia pós-consumo no Brasil. [Dissertação]. São Paulo: Universidade Metodista de Piracicaba, São Paulo; 2007. 303p.

RUIZ, M. S.; KNIESS, C. T.; TEIXEIRA, C. E. O setor de eletroeletrônicos: aspectos técnicos, econômicos, regulatórios e ambientais. São Paulo: UNINOVE, 2014, 257p.

SCARDUA, V. M. Educação infantil, educação ambiental e educação em valores: uma proposta de desenvolvimento moral da criança em relação às questões ambientais. Revista FACEVV, 2010,n. 4, p. $136-148$ 